\title{
Wound bed preparation for skin transplantation in chronic vein ulcers: A clinical case
}

\author{
Corresponding author: \\ Greta Mickevičiūtè, Clinic of Cardiac \\ and Vascular Diseases, Institute of \\ Clinical Medicine, Faculty of Medicine, \\ Vilnius University, \\ M. K. Ciurlionio 21 \\ LT-03101 Vilnius, Lithuania, \\ e-mail: gretaa.mickeviciute@gmail.com
}

Medical Research Journal 2020;

Volume 5, Number 2, 116-119 10.5603/MRJ.a2020.0010

Copyright (C) 2020 Via Medica ISSN 2451-2591

\begin{abstract}
Introduction: Chronic vein ulcer treatment is a clinical challenge for vascular surgeons, which requires a complex approach.

Case presentation: A 75-year-old male patient came to our out-patient clinic with a chronic trophic ulcer for five years. The patient was previously unsuccessfully treated with zinc-gelatine impregnated bandages. Our treatment plan consisted of systemic antimicrobial therapy, which was prescribed by our clinical pharmacologist, surgical debridement, phlebectomy, as well as split-thickness skin transplantation. The patient was released from the hospital after 14 days. No signs of infection were seen during the healing time.

Conclusion: A complex approach is recommended while treating chronic vein ulcers. Skin grafting reduces the duration and cost of the treatment.

Key words: chronic vein ulcers; chronic wounds; wound infection; biofilm; debridement; skin grafting; split-thickness skin graft.
\end{abstract}

Med Res J 2020; 5 (2): 116-119

\section{Introduction}

A wound is damage to the integrity of the skin, mucous membranes, or organs resulting in a tissue defect and defective skin function. A chronic wound is a wound that is halted in the inflammatory stage of healing and is unable to continue the healing process [1]. It is very important to choose the right method for the treatment of a chronic wound because an inadequate treatment method can disrupt wound healing completely. Some authors suggest that vein ulcers exceeding a diameter of $50 \mathrm{~cm}^{2}$ and open for more than six months cannot be treated only by conservative means and skin transplantation with surgical treatment on veins should be considered [2]. Split-thickness skin grafts remain the gold standard for the surgical treatment of venous ulcers [3].

\section{Case presentation}

On $13^{\text {th }}$ March 2018 a 75-year-old male patient came to our out-patient clinic with chronic trophic ulcer for five years. The venous origin of the trophic ulcer was approved by the clinical course: of course - a visible

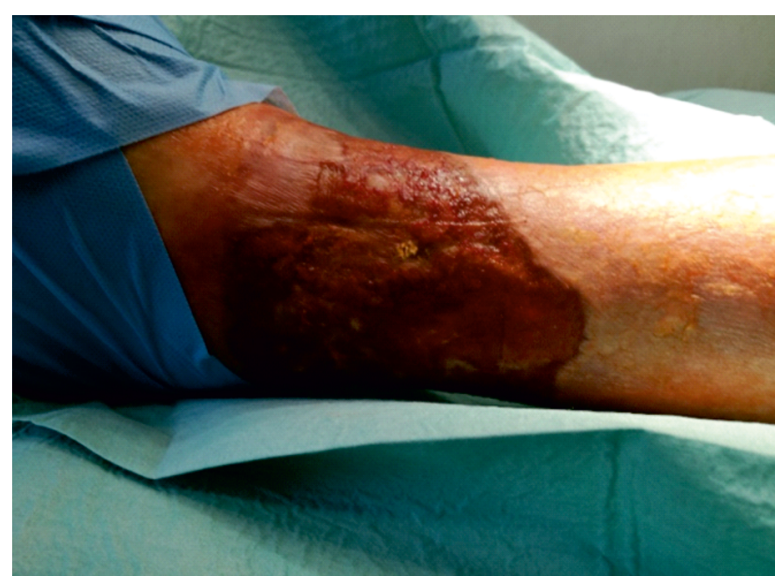

Figure 1. Chronic venous ulcer of the left ankle - visible biofilm and signs of infection. The picture was taken on $14^{\text {th }}$ March 2018

non-healing ulcer of the left ankle, pain, swelling, and hyperpigmentation of the skin around it. The size of the ulcer was approx. $7 \times 15 \mathrm{~cm}\left(105 \mathrm{~cm}^{2}\right)$, and it was covered with biofilm (Fig. 1). Histopathological analysis performed on $14^{\text {th }}$ March 2018 confirmed the 


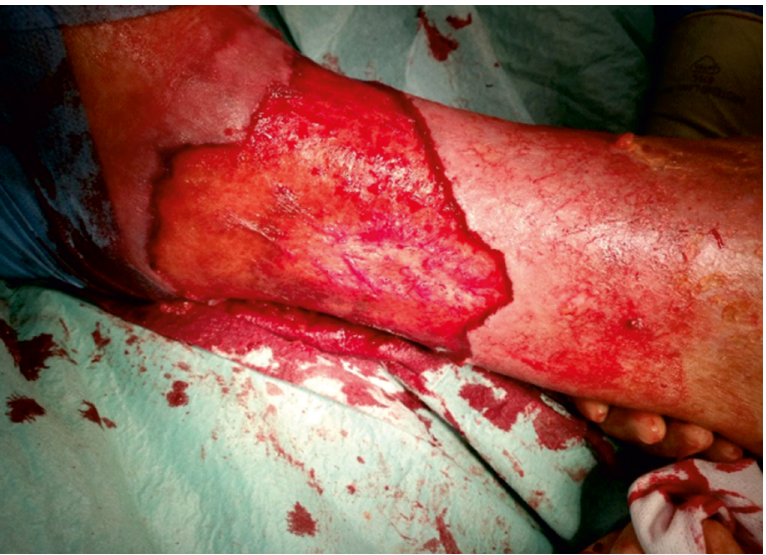

Figure 2. Surgical debridement of the ulcer performed on $14^{\text {th }}$ March 2018

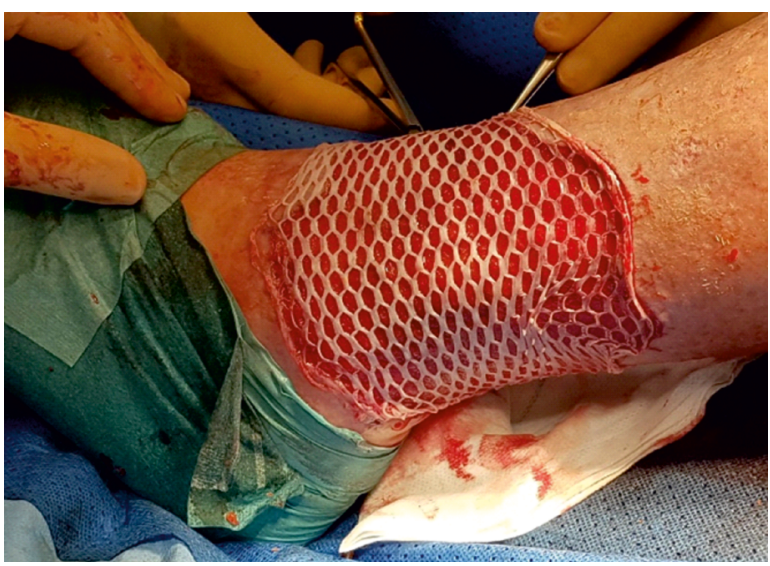

Figure 4. Skin transplantation with split-thickness skin graft performed on 22 ${ }^{\text {nd }}$ March 2018

diagnosis of chronic skin ulcer without any signs of a tumour. Ultrasonography showed insufficiency of the left great saphenous vein and chronic deep vein thrombosis of the left leg - femoral vein, popliteal vein, and calf veins. A culture from the ulcer revealed growth of several gram-positive and gram-negative bacteria: pseudomonas aeruginosa, Streptococcus constellatus, Enterococcus faecalis, and Bacteroides fragilis. Blood test showed elevated CRP (13.1 mg/L). No signs of peripheral artery disease were discovered - the patient had strong distal pulses. He also had chronic atrial fibrillation and primary arterial hypertension. The patient was previously unsuccessfully treated with zinc-gelatine impregnated bandages. Our treatment plan consisted of systemic antimicrobial therapy, which was prescribed by our clinical pharmacologist, surgical debridement, phlebectomy, as well as split-thickness skin transplan-

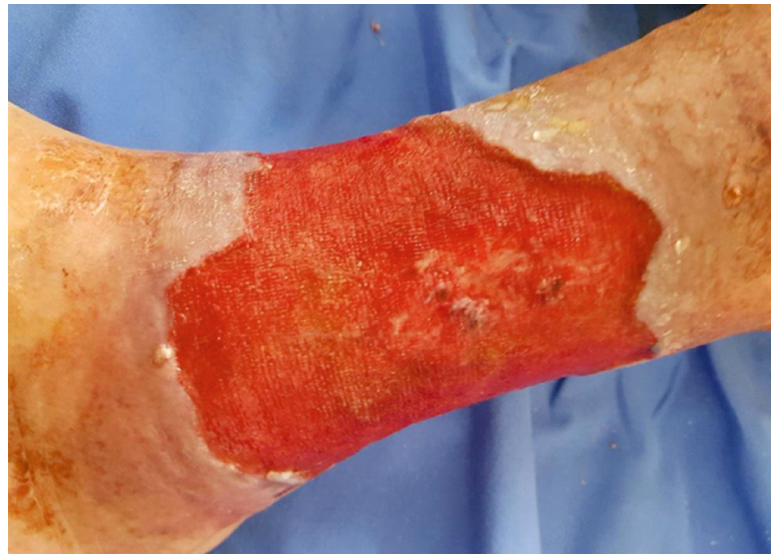

Figure 3. First day after surgical debridement - signs of granulation tissue on the wound bed. The picture was taken on $15^{\text {th }}$ March 2018

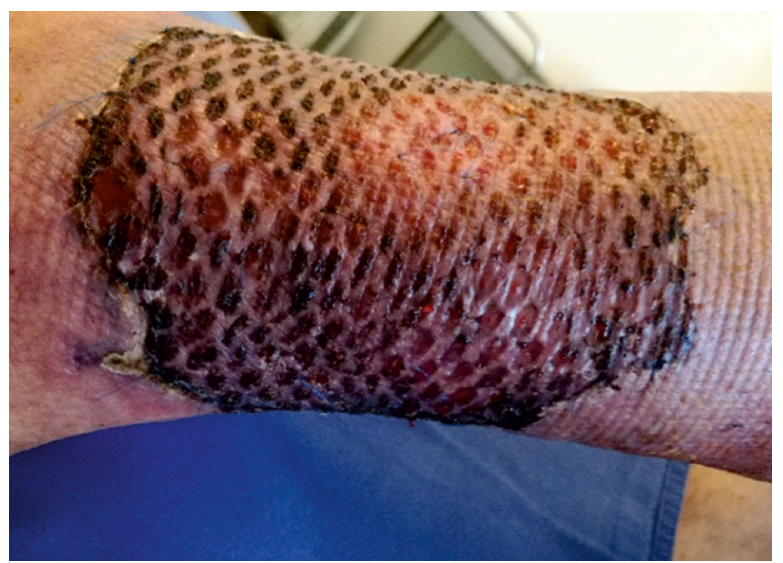

Figure 5. Changing the wound dressing 5 days postoperatively. The picture was taken on $27^{\text {th }}$ March 2018

tation. Surgical debridement was performed on $14^{\text {th }}$ March 2018 (Fig. 2). Microbiological analysis was repeatedly taken during the procedure, and on $21^{\text {st }}$ March the results showed no bacterial growth, one day prior to skin transplantation. There were signs of granulation on the wound bed one day postoperatively (Fig. 3). The patient was operated by performing phlebectomy of the left great saphenous vein and transplanting a split-thickness $0.4 \mathrm{~mm}$ skin graft, which was taken from the lateral surface of the left thigh. Before transplantation, visible non-viable tissue was repeatedly removed from the wound bed. The transplant was fixated with 6-0 Prolene sutures and paraffin net. The transplanted and donor sites were bandaged using sterile saline solution gauze bandages (Fig. 4). Five days after the operation the patient was re-bandaged using sterile saline solution gauze bandages (Fig. 5). He was released from the hos- 


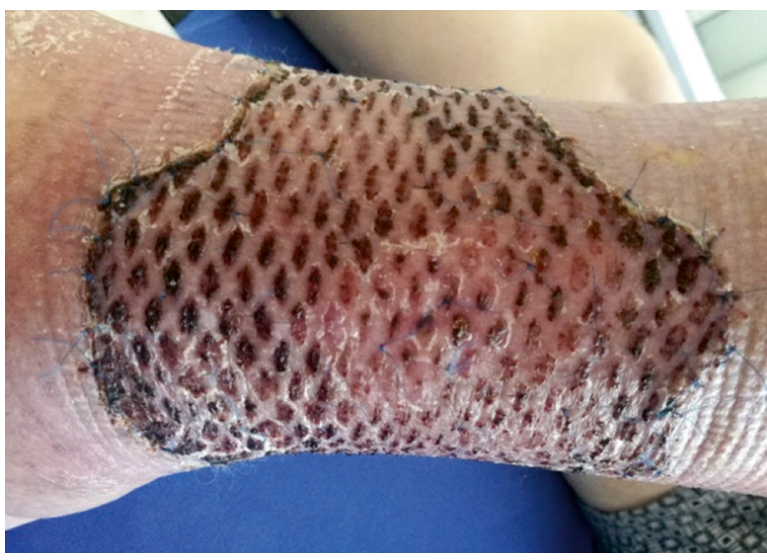

Figure 6. Changing the wound dressing 3 weeks postoperatively. The picture was taken on $10^{\text {th }}$ April 2018

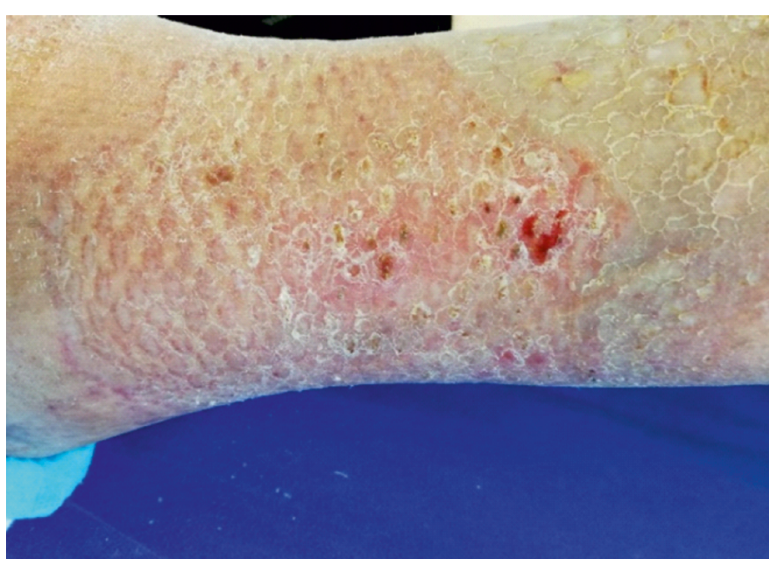

Figure 8. Changing the wound dressing 8 weeks postoperatively. The picture was taken on $15^{\text {th }}$ May 2018

pital on the same day with a total hospitalisation time of 14 days. The donor area was cured by bandaging it with sterile gauze bandages. The patient was re-bandaged in two weeks postoperatively in the same way as the first time and later repeatedly re-bandaged four more times: at three weeks (Fig. 6), seven weeks (Fig. 7), eight weeks (Fig. 8), and 12 weeks (Fig. 9) postoperatively using silver containing hydro fibre dressing for the transplanted site. The sutures and paraffin net were removed on the third appointment three weeks post-op. No signs of infection were seen during healing time.

\section{Discussion}

Venous ulcers exist in $1 \%$ of the general population, and the numbers have remained stable in many different

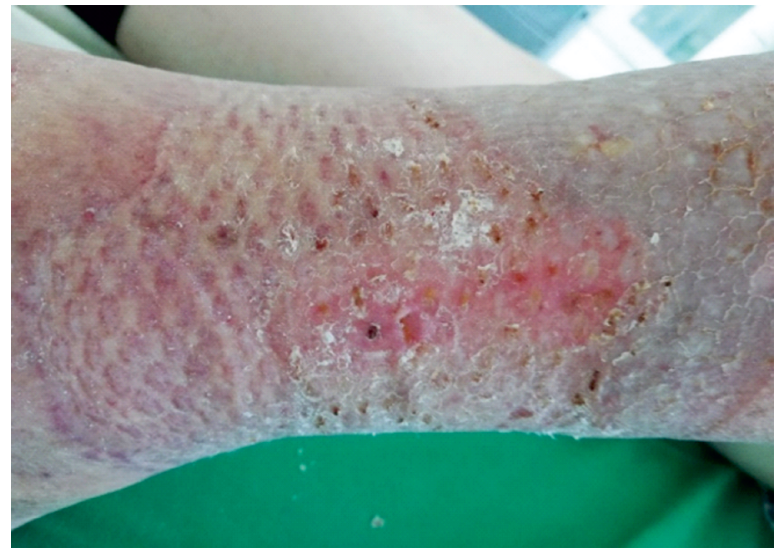

Figure 7. Changing the wound dressing 7 weeks postoperatively. The picture was taken on $8^{\text {th }}$ May 2018

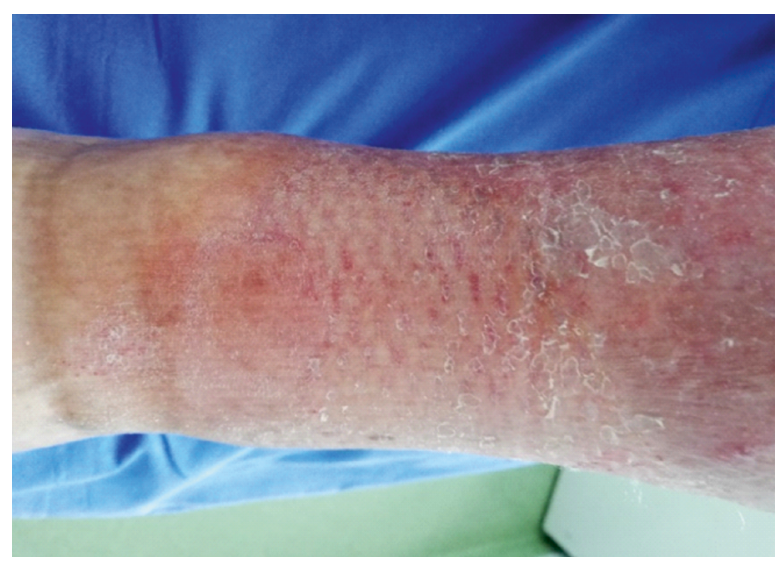

Figure 9. Changing the wound dressing 12 weeks postoperatively. The picture was taken on $12^{\text {th }}$ June 2018

countries over time $[4,5]$. They occur in the majority of chronic ulcer cases - approximately 70-90\% [6]. To date, compression therapy remains the main treatment for venous ulcers. Compression bandages should be applied before and throughout any other outpatient treatment. ${ }^{7}$ In addition, compression is crucial for preventing the recurrence of ulcers. A systematic review conducted in 2019 confirmed that wearing compression socks in patients with healed venous ulcers reduces the risk of reulceration by half [8].

A systematic review conducted in 2017 concluded that a partial skin thickness graft remains the gold standard for operative treatment of venous ulcers that exceed $50 \mathrm{~cm}^{2}$ and are open for more than six months. Compared to venous ulcers, the success rate of skin grafting in other types of chronic wounds is significantly lower [10]. 
In our clinic we support a wide and complex approach for patients with chronic wounds. The most important components of wound bed preparation for healing are debridement and removal of bacterial infection. Debridement is particularly important before skin grafting because the graft can only attach to a viable, sufficiently exposed layer of dermis, or to granular tissue. Usually, bacterial biofilm is found in chronic wounds, and thus the need for aggressive and proper debridement as well as systemic antimicrobial treatment is very important. There are lots of different debridement techniques, although we use and advocate simple and cheap surgical debridement most of the time. Also, in 2015 the European Association for Microbiology and Infectious Diseases recommended the use of a complex biofilm treatment using surgical debridement and antimicrobial dressings with silver, honey, iodine, or acetic acid [9].

By performing a surgical debridement procedure and excluding existing infection we were prepared for the next step: removing insufficient veins and transplanting the skin graft. This complex treatment led us to a successful outcome which was not achieved by treating this patient conservatively.

\section{Conclusion}

Due to a long and expensive venous leg ulcer treatment we adjusted to a complex approach: we removed the bacterial biofilm with surgical debridement and systemic antimicrobial therapy and performed phlebectomy and split-thickness skin transplantation. The skin grafting not only let us to cure the trophic venous ulcer, which was not successfully treated by conservative means, but also significantly reduced the duration of the treatment. This treatment plan not only helped our patient to maintain his everyday life but also reduced the cost of the treatment.

\section{Ethical approval}

Approved by Vilnius University Hospital Santaros Clinics Ethics committee

\section{Consent}

Written consent was given by the patient

\section{Funding}

No funding source to declare

\section{Conflict of interest}

None

\section{Previously presented}

Vilnius Vascular Symposium in Vilnius, Lithuania, 2019.

\section{References:}

1. Attinger $\mathrm{C}$, Wolcott R. Clinically Addressing Biofilm in Chronic Wounds. Adv Wound Care (New Rochelle). 2012; 1(3): 127-132, doi: 10.1089/wound.2011.0333, indexed in Pubmed: 24527292.

2. Margolis DJ, Berlin JA, Strom BL. Which venous leg ulcers will heal with limb compression bandages? Am J Med. 2000; 109(1): 15-19, doi: 10.1016/s0002-9343(00)00379-x, indexed in Pubmed: 10936473.

3. Wax MK, Pittman AL, Ghanem TA. Split-thickness skin grafts: overview, graft selection, donor site selection, wound preparation, operative technique, graft survival, graft failure, biological skin substitutes. Medscape. 2019

4. Bobek K, Cajzl L, Cepelak V, et al. Étude de la fréquence des maladies phlébologiques et de I'influence de quelques facteurs étiologiques. Phlebologie. 1966; 19: 227-230.

5. Widmer LK. Peripheral Venous Disorders. Basle Study III. Hans Huber, Bern 1978.

6. Snyder RJ. Treatment of nonhealing ulcers with allografts. Clin Dermatol. 2005; 23(4): 388-395, doi: 10.1016/j.clindermatol.2004.07.020, indexed in Pubmed: 16023934

7. Cronenwett JL, Johnston KW. (ed.). Rutherford's Vascular Surgery, 8th ed. Saunders Elsavier, Philadelphia 2014.

8. Djalalov S, Sehatzadeh S, Keast DH, et al. Health Quality Ontario Compression Stockings for the Prevention of Venous Leg Ulcer Recurrence: A Health Technology Assessment. Ont Health Technol Assess Ser. 2019; 19(2): 1-86, indexed in Pubmed: 30828407.

9. Bjarnsholt T, Eberlein T, Malone M, et al. et.al. Management of wound biofilm made easy. Wounds UK. 2017; 8(2): 1-6.

10. Serra R, Rizzuto A, Rossi A, et al. Skin grafting for the treatment of chronic leg ulcers - a systematic review in evidence-based medicine. Int Wound J. 2017; 14(1): 149-157, doi: 10.1111/iwj.12575, indexed in Pubmed: 26940940. 